\title{
ELECCIONES PRESIDENCIALES EN PORTUGAL
}

El general Antonio dos Santos Ramalho Eanes ha sido reelegido para el cargo de Presidente de la República de Portugal en las elecciones presidenciales celebradas el día 7 de diciembre en aquel país, prorrogando, de esta manera, su mandato por cinco años.

A este respecto, la Constitución portuguesa dice:

Art. 124: El Presidente de la República será elegido por sufragio universal directo y secreto de los ciudadanos portugueses con derecho a voto, censados en el territorio nacional.

Art. 129: Será elegido Presidente de la República el candidato que obtenga más de la mitad de los votos válidamente emitidos.

Si ninguno de los candidatos obtuviese dicho número de votos se procederá a una segunda votación a los veintiún días siguientes a la primera.

A esta votación se presentarán solamente los dos candidatos que hayan tenido más votos y que no hayan retirado su candidatura (caso idéntico al de Francia).

Art. 131: El mandato del Presidente de la República tendrá una duración de cinco años y terminará con la toma de posesión del nuevo Presidente electo.

El general Eanes no necesitó de la segunda vuelta para conseguir la reelección, pues ya en la primera votación alcanzó la mayoría necesaria para acceder al cargo.

Pero antes de entrar en detalles sobre el resultado de esta consulta electoral - la segunda que se celebra en el transcurso de tres meses en Portugal, siendo las primeras las elecciones legislativas del 5 de octubre- quiero hacer destacar algunas de las circunstancias que rodearon a esta convocatoria a las urnas.

En primer lugar, estas elecciones presidenciales se celebraban en un ambiente de euforia en un sector político y de frustración en otro, pues solamente dos meses antes se habían llevado a cabo las elecciones a la Asamblea de la República, registrándose - por primera vez desde la Revolución de abril- una victoria no sólo en el total de escaños conseguidos, sino también en el número de votos populares del conjunto de la derecha y el centro, coaligados en Alianza Democrática, sobre el conjunto de los escaños y votos populares de la izquierda ${ }^{1}$.

${ }^{1}$ Cfr. Fernando Ollero Butler, Las elecciones legislativas del 5 de octubre en Portugal, en «Revista del Departamento de Derecho Político», núm. 8, 1980. 
En segundo lugar es bien sabido que, tanto en su campaña electoral previa a las elecciones legislativas como tras su triunfo en éstas, Alianza Democrática, a través de su líder, Francisco Sa Carneiro, no dejó de manifestar su intención de reformar la Constitución, y la presencia del general Eanes en la Presidencia de la República constituía un tremendo obstáculo para la realización de este propósito. De aquí su incondicional apoyo al único candidato con posibilidades reales de desplazar a Eanes: el general Soares Carneiro.

En tercer lugar, un dramático acontecimiento vino a ensombrecer los últimos días de la campaña electoral de los candidatos a la Presidencia: la trágica muerte en accidente de aviación del máximo dirigente de Alianza Democrática y primer ministro, Francisco $\mathrm{Sa}$ Carneiro, cuando se disponía a trasladarse a Oporto para proseguir la campaña en favor de Soares Carneiro.

La campaña electoral estuvo salpicada frecuentemente por incidentes entre grupos de ideología política distinta. Además, la virulencia de los ataques entre los candidatos a la elección superó con mucho a la registrada en anteriores comicios. Las acusaciones de filocomunismo lanzadas por los dirigentes de Alianza Democrática contra Eanes obligaron a éste a desmarcarse de un Partido Comunista que, no obstante, engrosaría con sus militantes y seguidores los mítines y demostraciones en favor de Eanes, tras la retirada de su candidato.

Los candidatos a la Presidencia de la República fueron los siguientes:

- Antonio dos Santos Ramalho Eanes: Presidente de la República desde las presidenciales del 26 de junio de 1976, en las que acaparó el 61,5 por 100 de los votos, apoyado por el Partido Socialista y el entonces Partido Popular Democrático de Sa Carneiro. En esta ocasión era apoyado por socialistas, socialdemócratas, independientes y comunistas.

- Antonio da Silva Osorio Soares Carneiro: católico y anticomunista visceral; era el candidato de Alianza Democrática y, como ya se ha dicho, el único capaz de derrotar a Eanes.

- Antonio Elisio Capelo Pires Veloso: con una opción parecida a la de Soares Carneiro; contaba con una cierta incidencia en el norte conservador del país.

- Carlos Galvao de Melo: «apóstol de la Hermandad de Clases»; sus posibilidades fueron nulas desde un principio.

- Otelo Nunho Romao Saraiva de Carvalho: prometió la formación de una mayoría de izquierdas para reimplantar la «Revolución del Clavel». Le apoyó la mayoría de la extrema izquierda.

- Carlos Alfredo de Brito: líder del grupo parlamentario comunista; retiró su candidatura en favor de Eanes.

- Aires Rodrigues: fue diputado del Partido Socialista antes de ser expulsado del mismo. Apoyado por el Partido Obrero de Unificación Socialista (trotskista).

Ofrezco a continuación los resultados definitivos y oficiales de la consulta electoral del 7 de diciembre pasado (cuadro 1), además de un cuadro comparativo de los votos alcanzados por los dos candidatos más votados y los votos conseguidos en las legislativas del 5 de octubre por los partidos que dieron su apoyo a los dos candidatos en las pasadas presidenciales (cuadro 2). 


\section{Cunaro 1}

\begin{tabular}{|c|c|c|}
\hline Candidatos & Votos & $\%$ \\
\hline Antonio Ramalho Eanes & 3.249 .296 & 56,43 \\
\hline 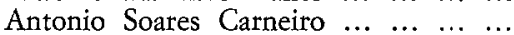 & 2.319 .841 & 40,25 \\
\hline Otelo Saraiva de Carvalho $\ldots . . . . . .$. & 85.181 & 1,48 \\
\hline Carlos Galvao de Melo $\ldots . . . . . . . . . .$. & 48.359 & 0,84 \\
\hline Antonio Pires Veloso $\ldots . . . .$. & 44.961 & 0,78 \\
\hline Antonio Aires Rodrigues $\ldots \ldots \ldots$ & 12.628 & 0,22 \\
\hline Participación electoral & 5.821 .937 & 84,13 \\
\hline $\begin{array}{lllllllll}\text { Abstención } & \ldots & \ldots & \ldots & \ldots & \ldots & \ldots & \ldots & \ldots\end{array}$ & 1.095 .615 & 15,87 \\
\hline
\end{tabular}

Fuente: Embajada de Portugal.

CuAdro 2

\begin{tabular}{|c|c|c|c|c|c|c|}
\hline \multicolumn{3}{|c|}{ LEGISLATIVAS $5-\mathrm{X}-80$} & \multicolumn{4}{|c|}{ PRESIDENCIALES 7-XII-80 } \\
\hline Partidos & Votos & $\%$ & Candidatos & & Votos & $\%$ \\
\hline $\begin{array}{l}\text { A.D. } \cdots \\
\text { F.R.S. } * \text { A. P. U. }{ }^{* *} \cdots\end{array}$ & $\begin{array}{l}2.860 .028 \\
2.681 .451\end{array}$ & $\begin{array}{l}47,50 \\
44,53\end{array}$ & $\begin{array}{l}\text { S. Carneiro } \\
\text { R. Eanes ... }\end{array}$ & $\begin{array}{l}\ldots \\
\ldots\end{array}$ & $\begin{array}{l}2.319 .841 \\
3.249 .296\end{array}$ & $\begin{array}{l}40,25 \\
56,43\end{array}$ \\
\hline
\end{tabular}

* Frente Republicano y Socialista (Partido Socialista Portugués, Unión de la Izquierda Socialista y Agrupación Socialdemócrata).

** Alianza Pueblo Unido (Partido Comunista Portugués y Movimiento Democrático Portugués).

La participación electoral en las legislativas de octubre fue del 84,94 por $100^{2}$. En el caso que nos ocupa, la participación ha sido casi idéntica: el 84,13 por 100 .

A la vista de los datos del cuadro 1 se comprueba claramente que los dos únicos candidatos con incidencia sobre el electorado portugués eran los generales Eanes y Soares Carneiro, pues el total de los votos del resto de los candidatos suma tan sólo el 3,32 por 100 .

En el cuadro 2 se puede apreciar lo que se ha dado en llamar «indisciplina del voto de centro-derecha». Efectivamente, comparando los votos conseguidos por A. D. en las legislativas de octubre con los alcanzados por el candidato de esta misma coalición electoral en las presidenciales de diciembre vemos una diferencia de - 540.187 votos. Votos que, en su totalidad, han pasado a engrosar los del candidato de socialistas y comunistas, Eanes, quien incrementa en +567.845 los votos recibidos en conjunto por el F. R.S. (P.S.P.) y la A.P. U. (P.C. P.) en las legislativas de octubre.

Muchas han sido y serán las interpretaciones de esta «indisciplina» del electorado centro-derechista. Yo personalmente me atrevería a afirmar que el electorado de A.D. no es tan homogéneo como se ha llegado a asegurar, y que si bien dejó claro en octubre su deseo de que fuera el centro-derecha el que gobernara el país, no parece estar dispuesto a que sea reformada la Constitución, que, hasta el momento, ha posibilitado el desarrollo de la convivencia democrática en Portugal.

\section{${ }^{2}$ Ibid.}

